\title{
Aerosol-induced correlation between visibility and atmospheric electricity.
}

Article

Harrison, R.G. (2012) Aerosol-induced correlation between visibility and atmospheric electricity. Journal of Aerosol Science, 52. pp. 121-126. ISSN 0021-8502 doi: https://doi.org/10.1016/j.jaerosci.2012.04.011 Available at https://centaur.reading.ac.uk/28087/

It is advisable to refer to the publisher's version if you intend to cite from the work. See Guidance on citing.

To link to this article DOI: http://dx.doi.org/10.1016/j.jaerosci.2012.04.011

Publisher: Elsevier

All outputs in CentAUR are protected by Intellectual Property Rights law, including copyright law. Copyright and IPR is retained by the creators or other copyright holders. Terms and conditions for use of this material are defined in the End User Agreement.

\section{www.reading.ac.uk/centaur}

\section{CentAUR}

Central Archive at the University of Reading

Reading's research outputs online 


\title{
Aerosol-induced correlation between visibility and atmospheric electricity
}

\section{R.G. Harrison}

Department of Meteorology, University of Reading

PO Box 243, Earley Gate, Reading, RG6 6BB

\section{Accepted for publication in Journal of Aerosol Science}

DOI: http://dx.doi.org/10.1016/j.jaerosci.2012.04.011

\begin{abstract}
Summary
Atmospheric aerosol acts to reduce the background concentration of natural cluster ions, and to attenuate optical propagation. Hence, the presence of aerosol has two consequences, the reduction of the air's electrical conductivity and the visual range. Ion-aerosol theory and Koschmieder's visibility theory are combined here to derive the related non-linear variation of the atmospheric electric potential gradient with visual range. A substantial sensitivity is found under poor visual range conditions, but, for good visual range conditions the sensitivity diminishes and little influence of local aerosol on the fair weather potential gradient occurs. This allows visual range measurements, made simply and routinely at many meteorological sites, to provide inference about the local air's electrical properties.
\end{abstract}

Keywords: air pollution; fog; atmospheric electricity; potential gradient; 


\section{Introduction}

The optical and electrical properties of air both respond to aerosol, in the form of numerous small particles present in haze and aerosol pollution and the larger droplets present in smog, fog and low cloud. Such particles reduce the visual range ${ }^{1}$, and remove natural background cluster ions mostly responsible for air's electrical conductivity. The common origin of these electrical and optical changes implies a non-causal correlation between the visual range and atmospheric electrical properties. Visual range information therefore indicates whether local aerosol effects are also likely to be influencing the atmospheric electrical measurements, such as that of the potential gradient. Negligible local aerosol effect is required if the potential gradient measurements are to be regarded as those of fair weather, which is, in turn, one condition necessary for considering them globally representative.

Fair weather atmospheric electricity conditions were defined by the Met Office (HMSO, 1964), as circumstances showing all of the following: (1) no hydrometeors, (2) no low stratus cloud, (3) less than three-eighths cumuliform cloud and (4) mean hourly wind speed less than $8 \mathrm{~ms}^{-1}$. Good visual range can be expected to be associated with conditions (1) and (2). When limited (or no) local meteorological data exist, as in the case of historical atmospheric electricity analysis (Harrison, 2006; Aplin, 2012), visual range data may therefore offer additional useful context. The use of automatic visual range instrumentation, such as transmissometers or present weather detectors, provides a further potential data source.

Expectation of a relationship between optical and electrical properties is supported by observations, as, even in early measurements of ion concentration, air clarity was also noted (Simpson, 1906). On hourly timescales, Ruhnke (1966) reported a positive correlation between visibility and ion number concentration, and Manes (1977) showed coincident decreasing annual trends in visibility and conductivity. Tsunoda and Satsutani (1977) found increases in visibility coincident with both an increase in air conductivity and particle number concentration decreases. Brazenor and Harrison (2005) also found a close empirical relationship between air conductivity and visibility, for urban air.

Here, theoretical aerosol-conductivity and aerosol-visibility relationships are considered together for fog droplets, which are compared with routine visual range and atmospheric electricity measurements of potential gradient.

\section{Theory}

The correlation between visual range and conductivity is investigated by considering the independent theories for the visibility and conductivity effects of a concentration of droplets.

\subsection{Visual range}

With visible light, the important scattering particles are large compared with the wavelength, and the wavelength dependence can be neglected. For a parallel beam of irradiance I passing through a

\footnotetext{
${ }^{1}$ Visual range is also known commonly as visibility; it is the greatest distance at which an object can be seen and recognised.
} 
thickness $\mathrm{d} x$ of scattering material such as fog-laden air, the reduction in irradiance is given by Beer's law,

$$
\mathrm{d} l=-\xi l(x) \mathrm{d} x \quad \text { Equation } 1
$$

where $\xi$ is an extinction coefficient (with dimensions of inverse length). For extinction which is independent of $x$, integration gives

$$
I=I_{0} \exp (-\xi x) \quad \text { Equation } 2 .
$$

Assuming an extinction cross-section for droplets of approximately twice their projected area (e.g. Bohren and Huffman, 1983), the total extinction coefficient, when there are $N$ drops of diameter $D$ per unit volume, is

$$
\xi=N \frac{\pi}{2} D^{2}
$$

Equation 3.

However, the extinction coefficient alone is insufficient to determine the visual range, as the optical contrast required to identify an object at a given visual range is also needed. Koschmieder (1924) related the visual contrast between an object and its surroundings to the optical scattering properties of the intervening atmosphere. For a dark object at a distance $X$ viewed against a light background, the visual contrast $C$ at an observer's eye is

$$
C=\exp (-\xi X) \quad \text { Equation } 4 .
$$

As $X$ increases, the contrast $C$ between the dark object and its light background decreases until $C$ equals a critical value $\varepsilon$. At this critical value of contrast the object can no longer be distinguished from its surroundings and the object is then considered to be at the visual range $X_{\mathrm{r}}$. Thus

$$
\varepsilon=\exp \left(-\xi X_{\mathrm{r}}\right) \quad \text { Equation } 5
$$

and, for the usually accepted $\varepsilon=0.05$ (HMSO, 1982), the visual range $X_{\mathrm{r}}$ is

$$
X_{r}=-\frac{\ln \varepsilon}{\xi}=\frac{3}{\xi}
$$

Equation 6.

Substituting gives a relationship between the visual range $X_{r}$, the droplet diameter $D$ and the droplet number concentration $N$, as

$$
X_{r}=\frac{6}{\pi N D^{2}}
$$

Equation 7.

\subsection{Atmospheric electricity}

The relationship between the droplet properties and the electrical properties of air depends on the ion balance equation, (e.g. Harrison and Carslaw, 2003; Clement and Harrison, 1992), in which turbulent effects on ion transfer (Law, 1963) are neglected. For air containing both droplets and aerosol, this becomes, in the steady-state, 


$$
q-\alpha n^{2}-\left(\beta_{a} n Z+\beta_{D} n N\right)=0
$$

Equation 8

where $n$ is the ion concentration, $Z$ the background aerosol concentration and $N$ the droplet concentration. ( $q$ is the ion production rate and $\alpha$ the ion-ion recombination rate.) The attachment coefficients for ion-aerosol and ion-droplet attachment are $\beta_{\mathrm{a}}$ and $\beta_{\mathrm{D}}$ respectively. For neutral particles of radius $a$, the attachment coefficient is given by Gunn (1954) as

$$
\beta=\frac{4 \pi k T \mu_{m}}{e} a
$$

Equation 9

where $k$ is Boltzmann's constant, $T$ the temperature, $\mu_{\mathrm{m}}$ the mean ion mobility and $e$ the elementary charge.

Solving Equation 8 for the mean ion concentration $n$ gives

$$
n=\frac{\left\lfloor\sqrt{\left(\beta_{a}^{2} Z^{2}+2 \beta_{a} Z \beta_{D} N+\beta_{D}^{2} N^{2}+4 \alpha q\right)}-\left(\beta_{a} Z+\beta_{D} N\right)\right\rfloor}{2 \alpha} \quad \text { Equation } 10
$$

from which, the total air conductivity $\sigma_{\mathrm{t}}$ varies as

$$
\sigma_{t}=\frac{\mu_{m} e}{\alpha}\left[\sqrt{\left(\beta_{a}^{2} Z^{2}+2 \beta_{a} Z \beta_{D} N+\beta_{D}^{2} N^{2}+4 \alpha q\right)}-\left(\beta_{a} Z+\beta_{D} N\right)\right] \quad \text { Equation } 11 .
$$

As the potential gradient is a rather more commonly measured quantity in fair weather atmospheric electricity than the air conductivity, it is useful instead to transform this result to potential gradient. This is straightforwardly found from Ohm's Law as $J_{z}=\sigma_{\mathrm{t}} F$, where $F$ is the potential gradient and $J_{z}$ the vertical conduction current density. Substituting for $N$ from Equation 7 allows $F$ to be related to the visual range $X_{r}$, as

$$
F\left(X_{r}\right)=J_{z}\left(\frac{\alpha}{\mu_{m} e}\right) \frac{1}{\left[\sqrt{\left(\beta_{a}^{2} Z^{2}+\frac{12 \beta_{D} \beta_{a} Z}{\pi D^{2} X_{r}}+\frac{36 \beta_{D}^{2}}{\pi^{2} D^{4} X_{r}^{2}}+4 \alpha q\right)}-\left(\beta_{a} Z+\frac{6 \beta_{D}}{\pi D^{2} X_{r}}\right)\right]}
$$

Equation 12.

This relationship between $F$ and $X_{\mathrm{r}}$ is non-linear, but, when $X_{\mathrm{r}}$ becomes large (i.e. during good visibility), the expression tends to a steady value of potential gradient $\left(F_{\infty}\right)$,

$$
F_{\infty}=J_{z}\left(\frac{\alpha}{\mu_{m} e}\right)\left[\frac{1}{\left[\sqrt{\left(\beta_{a}^{2} Z^{2}+4 \alpha q\right)}-\left(\beta_{a} Z\right)\right]}\right.
$$

Equation 13,

which depends principally on the background aerosol properties $Z$ and $a$, as $J_{z}, \mu_{\mathrm{m}}, q$ and $\alpha$ show much less relative variability in typical continental conditions. The fog effect falls off as the ion-loss to background aerosol begins to dominate over ion-loss to fog droplets, i.e. for $\beta_{\mathrm{D}} N<<\beta_{\mathrm{a}} z$. This begins at a critical visual range $X_{c}$, beyond which the PG perturbation is greatly diminished and approaches $F_{\infty}, X_{c}$ is given by 


$$
X_{c}=\frac{6}{\pi Z a D}
$$

Equation 14.

\section{Comparison with observations}

Figure 1 shows the relationships of (a) Equation 7 and (b) Equation 11, assuming an ion production rate $q=10 \mathrm{~cm}^{-3} \mathrm{~s}^{-1}$ and mean ion mobility $\mu_{\mathrm{m}}=1.2 \mathrm{~cm}^{2} \mathrm{~V}^{-1} \mathrm{~s}^{-1}$ (Chalmers, 1967), and representing the background aerosol by monodisperse $\left(0.2 \mu \mathrm{m}\right.$ radius) particles of concentration $2500 \mathrm{~cm}^{-3}$. In (a) there is no consideration of the total liquid water content, hence, although it is apparent that the largest diameter drops would cause a large visual range reduction, the situation is somewhat unphysical and included only to bound the values considered; the 2 to $5 \mu \mathrm{m}$ diameter drops are more representative of a fog. Figure 1 (c) results from combining the data of (a) and (b) to show the correlated variation of visual range and conductivity. However, as mentioned, potential gradient is the most commonly observed atmospheric electricity quantity, and (d) shows the final relationship (Equation 12) in terms of potential gradient, assuming $J_{2}=2 \mathrm{pAm}^{-2}$ (Chalmers, 1967). The selection of values for $J_{z}$ and background aerosol properties $Z$ and $a$ serve to set the "good visibility" PG (Equation 13), and the values chosen do yield a steady potential gradient $\left(F_{\infty}\right)$ typical of fair weather. Inserting the same values in Equation 14 gives $X_{\mathrm{c}} \approx 760 \mathrm{~m}$ for $D=5 \mu \mathrm{m}$, and the asymptotic $F_{\infty}$ can be seen to be closely approached for $X>5 X_{c}$.

Equation 12 (Figure 1d) provides the basis for comparison with observations. At Reading Observatory, the visual range is recorded by the Meteorological observer at 9UT daily, with the potential gradient recorded continuously. Long term 9UT values of both potential gradient and visual range are therefore available for comparison, and Figure 2 shows histograms of these quantities. Visual range is recorded according to recognition of known objects at fixed distances, and reported in a coded form which only provides fairly coarse resolution. Because of this, only certain values of visual range are recorded, as evident from Figure 2 (b). For the lesser visual ranges $(<1 \mathrm{~km})$, improved resolution is available, but such poor visibility days are rare at Reading.

Grouping the 9UT potential gradient measurements according to the visual range measurement allows the distribution of potential gradient values at each visual range to be generated. Negative potential gradient measurements are first discarded, as these are usually due to precipitation (Harrison, 2011) during which the fair weather assumptions break down. Figure 3 shows the median of the potential gradient for each visual range. The median is used to reduce the sensitivity to outliers with variations in the sample size, and the standard error is also shown. During the low visibility typical of fog the potential gradient increases, and the good agreement may in part be related to the smaller spatial region effectively considered. As the visual range increases, the potential gradient becomes more typical of fair weather conditions (Harrison, 2011). Figure 3 includes over-plotted lines generated using Equation 12. These are not inconsistent with the observations, supporting the theoretical form derived and typical $J_{\mathrm{z}}$ and $\mu_{\mathrm{m}}$ parameters assumed in the calculations which are similar to those previously determined at the Reading Observatory site (Harrison and Aplin 2007; Bennett and Harrison, 2009). 
Few values exist in the Reading data during particularly poor visibility, when, due to the non-linearity in the relationship, the strongest sensitivity of PG to visual range occurs. Measurements of PG were, however made during the infamous London smog event of December 1952, at Kew Observatory in Richmond, west London (Harrison, 2006), which are probably amongst the most extreme PG values ever obtained during fog or smog. Hourly visual range measurements simultaneous with the Kew data were made at Heathrow (also in west London), which, for both the $6^{\text {th }}$ and $7^{\text {th }}$ December 1952, recorded 23 of the 24 hourly visual ranges as below $100 \mathrm{~m}$. (The visual ranges may of course have been considerably less than $100 \mathrm{~m}$, as suggested by the many photographic images available.) These extreme values are shown in Figure 4, which includes the Reading values of Figure 3 for comparison; it is apparent that the theoretical form remains consistent with the data over this extended range.

\section{Conclusions}

The close relationship between the electrical and optical properties of air can be understood in terms of common aerosol effects on both quantities, by combining the theoretical descriptions independently available in each case. This is validated by comparing potential gradient and visual range measurements made simultaneously, which supports the theoretical findings of a large sensitivity of potential gradient to visual range under poor visibility conditions, but a decreasing sensitivity with improved visibility. This close relationship between potential gradient and visual range implies that useful spatial information on the local atmospheric electrical state exists within the visual range.

\section{Acknowledgements}

The Meteorology Department's Observers generated the visual range data set analysed and DrC.D. Westbrook provided helpful comments. The Met Office made the Kew and Heathrow observations. The reviewers' comments are also gratefully acknowledged.

\section{References}

Aplin, K.L., 2012. Smoke emissions from industrial western Scotland in 1859 inferred from Lord Kelvin's atmospheric electricity measurements, Atmos Environ 50, 373-376 doi:10.1016/j.atmosenv.2011.12.053

Bennett, A. J., and R.G. Harrison, 2009. Evidence for global circuit current flow through water droplet layers, J. Atmos Solar-Terr Physics 71, 12, 1219-1221. doi:10.1016/j.jastp.2009.04.011 
Brazenor, T. J., and R.G. Harrison, 2005. Aerosol modulation of the optical and electrical properties of urban air. Atmos Environ 39, 5205-5212.

Bohren, C.F. and D.R. Huffman, 1983 Absorption and scattering of light by small particles, Wiley, New York

Chalmers, J.A., 1967. Atmospheric Electricity (2 ${ }^{\text {nd }}$ edition, Pergamon Press, London)

Clement, C.F., and R.G. Harrison, 1992. The charging of radioactive aerosols, J. Aerosol Sci 23, 5, 481504

Gunn, R., 1954. Diffusion charging of atmospheric droplets by ions and the resulting combination coefficients, J. Meteorol., 11, 339-347.

Harrison, R.G., 2006. Urban smoke concentrations at Kew, London, 1898-2004. Atmos Environ 40, 18, 3327-3332, doi: 10.1016/j.atmosenv.2006.01.042

Harrison, R.G., 2011. Fair Weather Atmospheric Electricity, J. Phys.: Conf. Ser. 301012001 doi: 10.1088/1742-6596/301/1/012001

Harrison, R.G., and K.L. Aplin, Water vapour changes and atmospheric cluster ions, Atmos Res 85, 199-208, (2007) doi: 10.1016/j.atmosres.2006.12.006

Harrison, R.G., and K.S. Carslaw, 2003. Ion-aerosol-cloud processes in the lower atmosphere, Rev.Geophys 41 (3), 1012, 10.1029/2002RG000114.

HMSO, 1964. The Observatories' Year Book, annual volume for 1964. Meteorological Office, Her Majesty's Stationery Office, London, UK

HMSO, 1982. Handbook of Meteorological Instruments, 7, (Measurement of visibility and cloud height), Meteorological Office, Her Majesty's Stationery Office, London, UK

Koschmieder, H., 1924. Theorie der horizontalen Sichtweite. Beitr Phys freien Atmos 12, 33-55

Law, J., 1963. The ionisation of the atmosphere near the ground in fair weather, Quart J Roy Meteor Soc 89, 107.

Manes, A., 1977. Particulate air pollution deduced from atmospheric electrical conductivity measurements at Bet-Dagan (Israel). In Dolezalek H., Reiter R., Electrical Processes in Atmospheres, Steinkopf Verlag, 109-118.

Ruhnke, L.H., 1966. Visibility and small-ion density. J. Geophys Res, 71, 4235-4241.

Simpson, G.C., 1906. Atmospheric electricity in high latitudes. Phil Trans. Roy. Soc. A 205, 61-97

Tsunoda, Y., and T. Satsutani, , 1977. Observation of atmospheric ions and atmospheric phenomena in the area of Kobe, Japan. In Dolezalek H., Reiter R., Electrical Processes in Atmospheres, Steinkopf Verlag, 135-142 
(a)

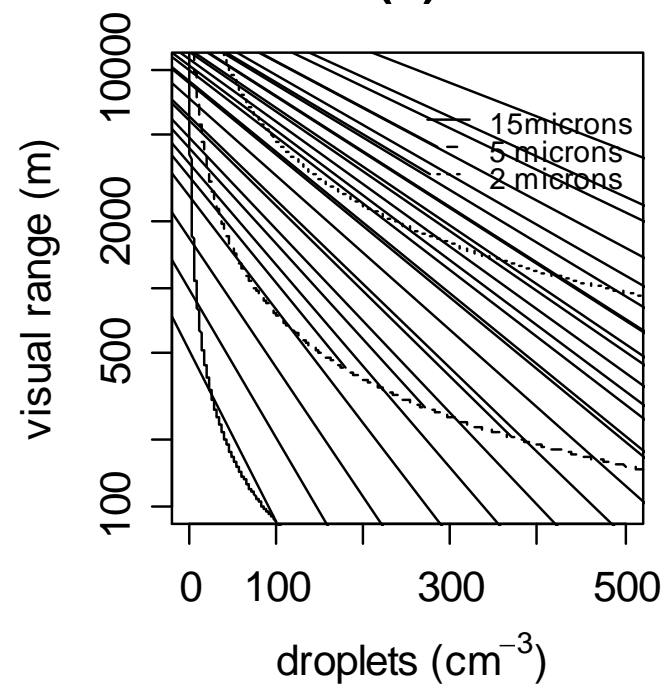

(b)

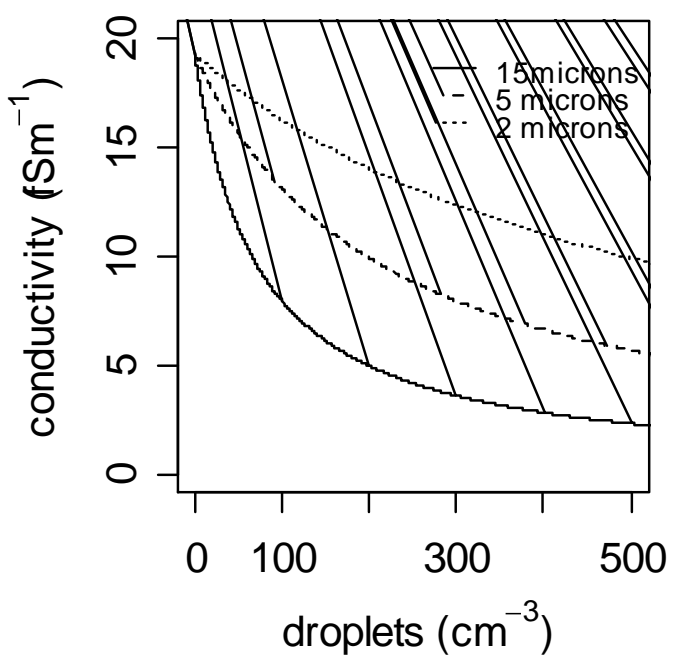

(c)

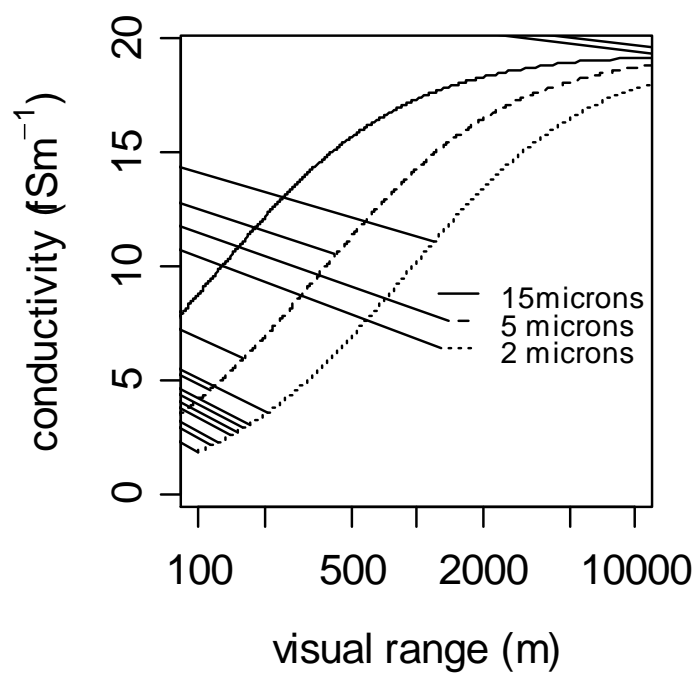

(d)

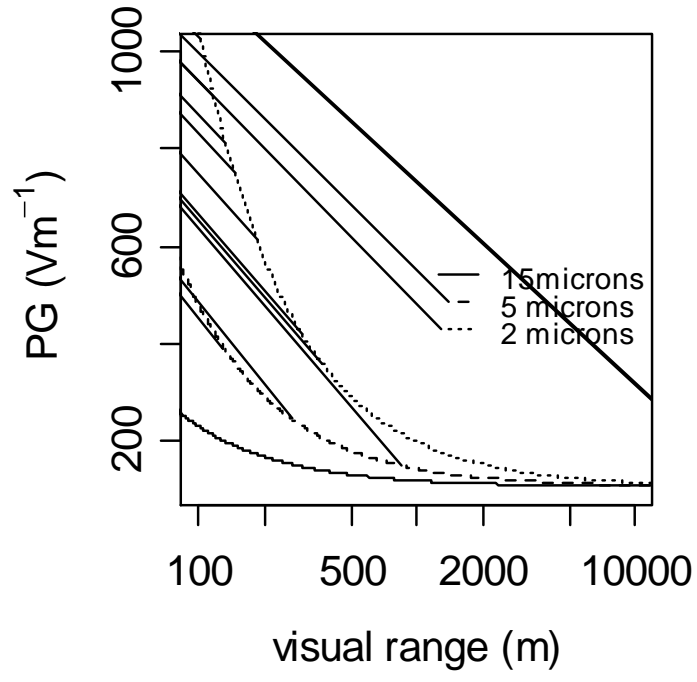

Figure 1 Calculation of the effect of water droplets (of diameters $15 \mu \mathrm{m}, 5 \mu \mathrm{m}$ and $2 \mu \mathrm{m}$ ) on, (a) the visual range and (b) the total air conductivity. (c) By combining (a) and (b) the relationship between total air conductivity and visibility can be found. (d) is the Potential Gradient derived from the total conductivity, assuming a conduction current density $J_{\mathrm{z}}=2 \mathrm{pAm}^{-2}$. (Background aerosol assumed to be of radius $0.2 \mu \mathrm{m}$, number concentration $2500 \mathrm{~cm}^{-3}$ and mean ion mobility $1.2 \mathrm{~cm}^{2} \mathrm{~V}^{-1} \mathrm{~s}^{-1}$.) 
(a)

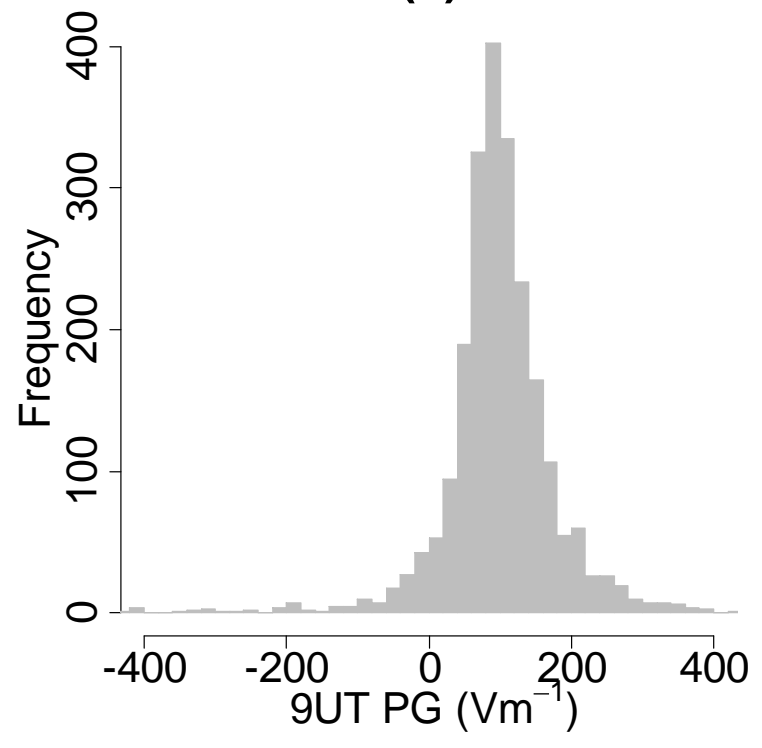

(b)

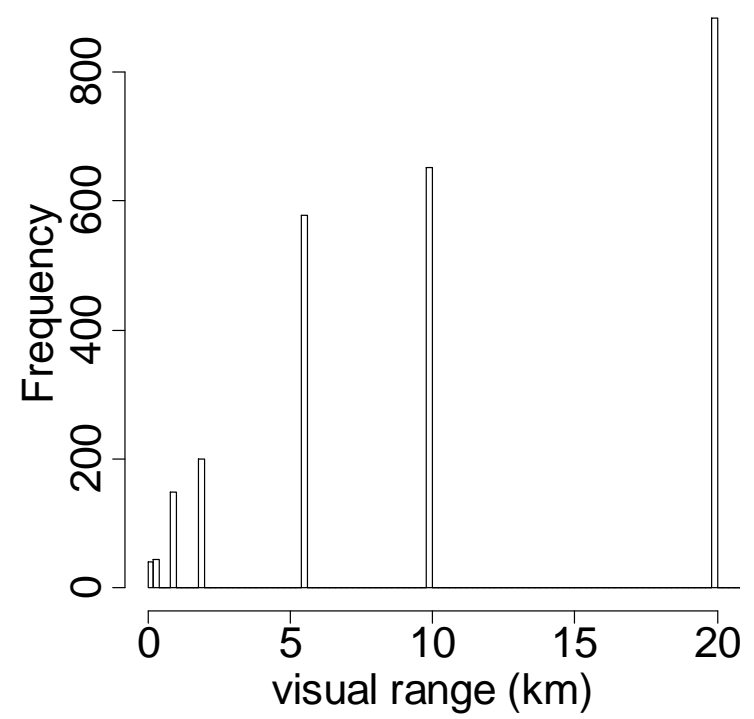

Figure 2 Distribution of daily 9UT measurements at Reading Observatory from 2005 to 2011 of (a) Potential Gradient (PG) and (b) visual range. 


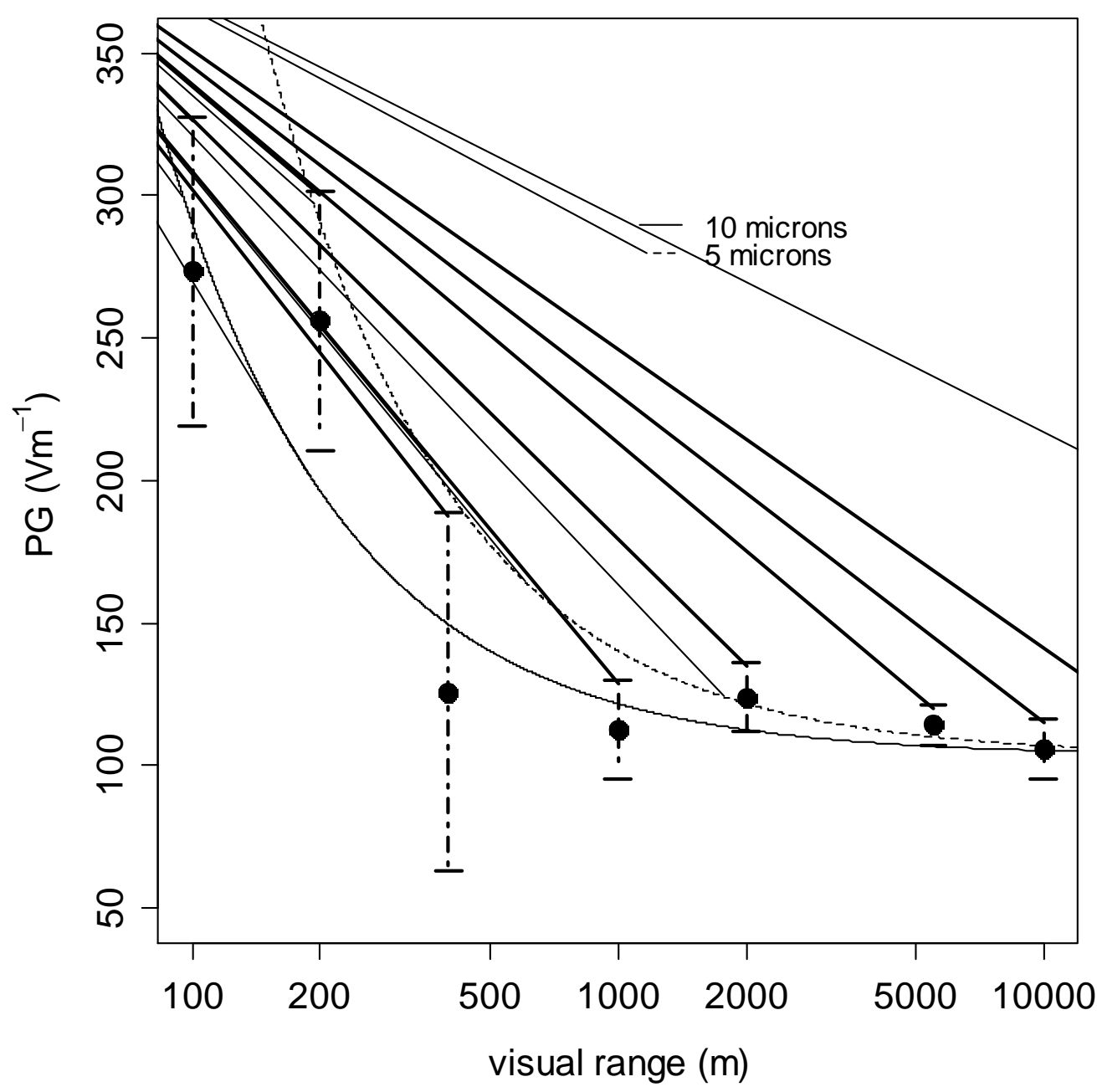

Figure 3. Median value of (positive) Potential Gradient (PG) recorded at Reading at 9UT, when grouped by simultaneous determination of visual range (points), with error bars extending to 2 standard errors (approximately $95 \%$ confidence) shown. Lines show the calculated PG, as for Figure 1 (d). 


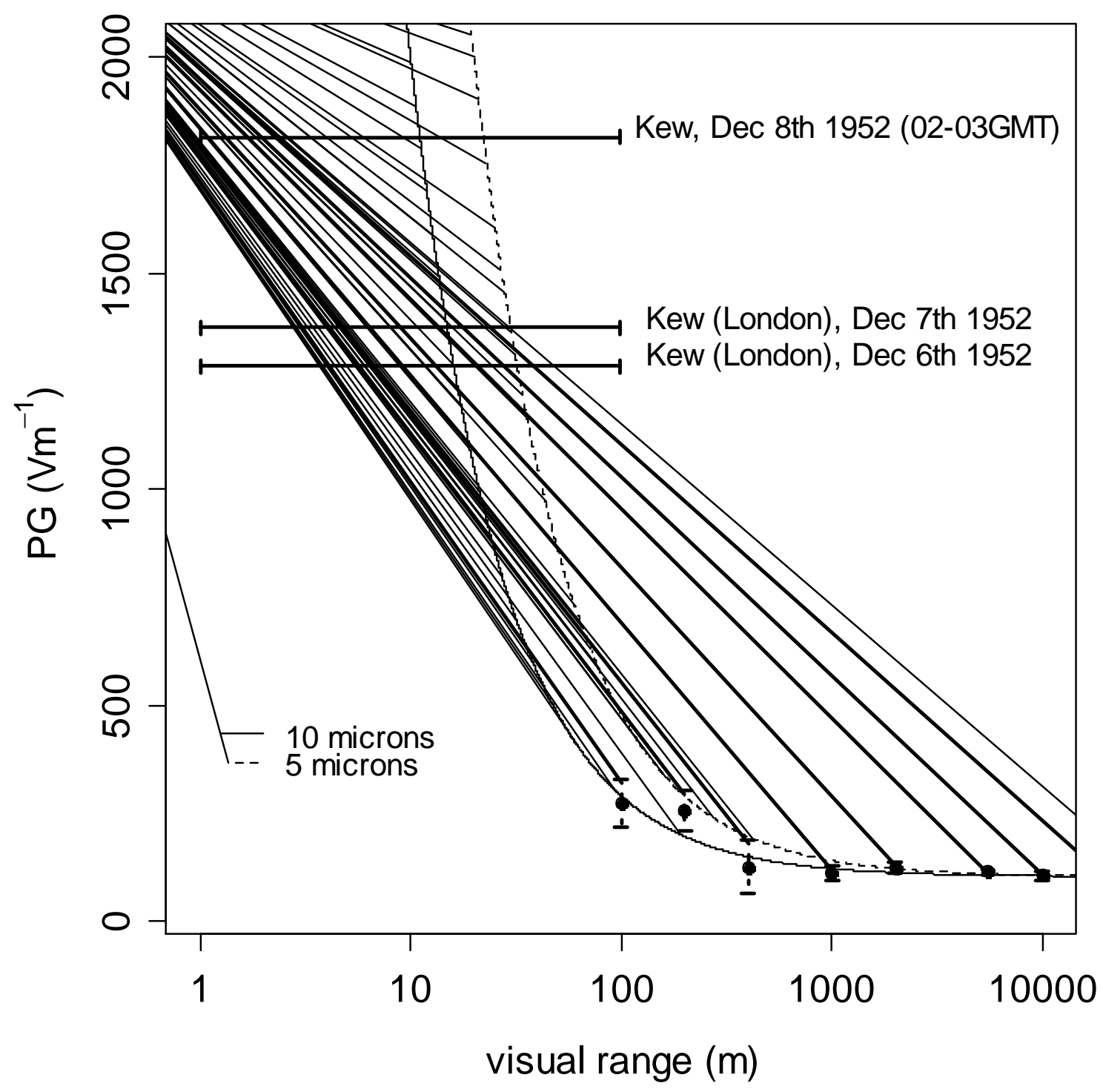

Figure 4. Calculated PG variation with visual range (black lines), including Reading Observatory data (points). Grey lines mark the extreme values of PG measured at Kew Observatory (Richmond, west London), during the December 1952 London smog episode, during which the median visibility at Heathrow was under $100 \mathrm{~m}$. 